\title{
TEKNIK FUSING PADA DAUR ULANG LIMBAH KANTONG PLASTIK DAN IMPLEMENTASINYA PADA DESAIN PRODUK
}

\author{
Devanny Gumulya S.Sn., M.Sc, Eliza Aristanto S. Sn \\ Universitas Pelita Harapan
}

\begin{abstract}
Abstrak : Saat ini Indonesia sudah menduduki posisi kedua penyumbang sampah plastik terbanyak setelah China. Melihat fakta - fakta ini maka, penelitian sebagai upaya untuk mendaur ulang kantong plastik perlu dilakukan. Teknik fusing adalah teknik menggabungkan dua atau lebih lembaran plastik dengan menggunakan panas. Dengan teknik fusing, limbah kantong plastik bisa menjadi material yang kuat dan tahan air. Material ini berpotensi untuk dijadikan produk fungsional salah satunya adalah produk dompet. Pendekatan yang digunakan pada penelitian ini adalah perancangan yang menekankan pada keunikan material limbah kantong plastik ini. Penelitian ini juga mengkaji persepsi dari material daur ulang ini. Kajian persepsi ini dibutuhkan agar material tidak lagi dipersepsikan sebagai sampah. Faktor emosi dan performative saling mempengaruhi. Persepsi material plastic fusing yang paling disukai responden adalah pola, warna kontras dan transparan. Hasil dari penelitian ini adalah rekomendasi desain merancang produk berbahan limbah kantong plastic dan produk seperti dompet dengan beberapa style yang mengekspresikan keunikan material ini.
\end{abstract}

\section{Kata Kunci: daur ulang, limbah kantong plastik, teknik fusing}

Abstract : Indonesia has become the second larget plastic waste contributor in the world after China. Saddens by this fact, this research is conducted to recycle plastic bag waste. Fusion technique is a technique to fuse two or more plastic plies by heating them. It is easily done because the equipment need is very easy to find. With fusion technique the plastic waste can be turned into durable and waterproof material. In this research, a card wallet is made out of the recycle material. Carry goods is a commodity that is continuously needed by market. The research used material driven design process, in which tries to explore the recycle material both in technical and experiential qualities. Aside from material exploration, this research also studies about user perception regarding this material, this study is needed to remove the waste stigma. From the study founded that emotional and performative are affecting each other. The three traits that user about plastic fusing material are pattern, contras color and transparency. The results are design recommendation on how to design using this new material and functional products like wallet designed with different style that express the material uniqueness.

Key Words: recycling, plastic bag waste, fusion technique.

\section{PENDAHULUAN}

Sampah plastiK sudah menjadi masalah dunia karena plastik mempunyai tingkat dekomposisi yang lambat, sehingga akan mengambang di laut selama bertahun-tahun. Plastik juga memiliki partikel yang bila hancur akan menjadi racun, sehingga akan mencemari tanah, air dan bahkan makhluk hidup lainnya. Oleh karena itu, Peneliti ingin melakukan observasi dan riset terhadap limbah plastik. Mengapa limbah kantong plastik? Limbah botol dan produk plastik dapat di recycle ulang kembali menjadi biji plastik dan umumnya menjadi produk dengan tingkat kualitas plastik yang lebih kurang, misalnya dari botol plastic didaur ulang melalui proses penggilingan kembali didapatkan biji plastik untuk memproduksi ember dll. Limbah kantong plastik jarang diulik, bahkan plastik supermarket yang dapat hancur, potongan - potongannya tidak akan terurai di tanah, bahkan bila masuk ke air potongan - potongan plastik ini dapat dimakan ikan, kura - kura ataupun burung. Menurut data dari ilmuwan di universitas Ghent Belgia (2018), bila manusia makan ikan dan burung yang mengkonsumsi mikroplastik secara terus menerus akan berdampak buruk pada kesehatan. Jadi dapat dikatakan limbah plastik ada di dalam tubuh kita. Oleh karena itu, ada dibuat plastik dari bahan natural, singkong, tapi harganya masih cukup mahal, dan tidak semua perusahaan mau mengadopsi 
kantong plastik bahan natural. Masih banyak perusahaan peritel menggunakan plastik yang tidak ramah lingkungan yang akhirnya menjadi limbah yang mencemari lingkungan.

Masalah yang mau dijawab di penelitian ini adalah:

- Bagaimana melakukan proses daur ulang limbah kantong plastik yang ditemukan sehari - hari dengan teknik fusing.

- Bagaimana material limbah kantong plastik yang sudah didaur ulang dengan teknik fusing diolah menjadi produk yang fungsional yang menekankan keindahan materialnya (material driven design)

Tujuan penelitian ini adalah mengetahui karakteristik limbah kantong plastic setelah di daur ulang dengan teknik fusing dan mempelajari kekuatan dan keindahan limbah kantong plastic yang sudah di daur ulang dengan teknik fusing dan menggali potensinya menjadi produk fungsional seperti kursi, tas yang bernilai desain dll.

\subsection{Material Driven Design (MDD)}

Material merupakan hal yang penting dalam riset dan praktek dalam desain produk (Ashby \& Johnson, 2009). Dalam rangka isu global warming dan pencemaran lingkungan yang semakin meningkat, riset tentang material alternatif pengganti material yang umum dipakai juga meningkat. Penelitian tentang material umumnya dalam konteks desain umumnya berfokus pada bagaimana membantu desainer memilih material dalam konteks bentuk dan teknologi produksinya (Ashby,1999; Ashby \& Cebon, 2007; Mangonon, 1999). Dalam beberapa tahun terakhir berkembang penelitian bagaimana material membentuk pengalaman kita berinteraksi dengan sebuah produk. (Ashby \& Johnson, 2009; Karana, 2009; Karana, Pedgley, \& Rognoli, 2014; Pedgley, 2009; Rognoli \& Levi, 2004; van Kesteren, 2008; Zuo, 2010). Dalam pemilihan material untuk menciptakan arti dari sebuah produk, terdapat beberapa faktor yang perlu diperhatikan, yaitu sifat sensoris dan teknis material, kemiripan material dan siapa pengguna atau target marketnya. Setiap faktor memiliki aspek-aspek lainnya yang juga perlu diperhatikan, misalnya untuk pengguna, terdapat aspek umur, jenis kelamin, keahlian, latar belakang budaya, dsb).

MDD adalah sebuah pendekatan dalam proses desain, dimana semua pengambilan keputusan desain didasarkan dari keunikan karakteristik material dengan tujuan meningkatkan pengalaman pengguna ketika berinteraksi dengan sebuah produk melalui dimensi material. Tujuan dari MDD adalah untuk mendukung para desainer bahwa material bisa dijadikan inspirasi dalam proses desain selain aspek fungsi.

\subsection{Tahapan Proses MDD}

Desainer produk diajarkan untuk mengikuti pendekatan sistematis untuk mengkonsepkan dan mengevaluasi ide sebelum ditranslasikan menjadi fungsi, bentuk, dan material pada desain akhirnya. Dalam MDD, proses desain tersebut dipertahankan. Berikut adalah langkah - langkah dalam MDD, menurut Karana, E., Barati, B., Rognoli, V., \& Zeeuw van der Laan, A. (2015).

\section{A. Tahap 1: Memahami properti teknis material dan karakteristik pengalaman material}

Tahap pertama dari MDD adalah pengertian akan material ini. Pada tahap ini desainer bertugas untuk lebih mengerti mengenai material yang ingin diriset lebih mendalam. Memahami material dalam kondisi sebelum diolah. Untuk mengetahui dan memahami material lebih dalam maka dapat dilakukan eksperimen pribadi terhadap material, serta melihat standar - standar yang sudah ada dsb. Terdapat 2 kategori hasil riset dalam tahap pertama ini. Yang pertama adalah riset material untuk 
mengetahui komponen teknisnya, dan yang kedua adalah untuk mengetahui komponen pengalaman yang dialami pengguna dari material tsb .

Komponen teknis dari material lebih memfokuskan riset terhadap material itu sendiri. Riset ini bisa dicapai dengan melakukan eksperimen terhadap material tersebut, seperti di bakar, di tarik, di banting, dll. untuk mengetahui struktur teknikal / fisik dari material tersebut, seperti seberapa kuat, seberapa tahan terhadap suhu dll. Diakhir eksperimen desainer harus dapat menjawab pertanyaan ini :

1. Karakter material sebelum diolah?

2. Apa kelebihan dan kekurangan material yang diriset sebelum dan sesudah diolah ?

3. Material bisa diproses dengan berapa teknik ? dan outputnya seperti apa ?

4. Teknologi produksi mana yang paling mudah dan cepat untuk memproses material tsb

Selanjutnya adalah pemahaman karakteristik pengalaman material, menurut (Giaccardi \& Karana, 2015) kualitas pengalaman dari material dapat dianalisa dalam 4 level yaitu : sensorial, interpretasi (makna), afektif (emosi), performatif (aksi dan performa). Sebagai contoh, ekspresi seseorang ketika melihat material yang diriset: wow (afektif), aneh ya (interpretasi), halus sekali (sensori), pengguna coba menekuk, melipat (performa)

Keempat level pengalaman ini dapat ditanyakan melalui rangkaian pertanyaan sbb:

Sensorial :

- Keunikan dimensi sensorial apa yang dimiliki material yang diriset?

- Dimensi sensorial apa yang paling dan tidak disukai dari material yang diriset?

- Apakah ada material lain yang mirip secara estetika dengan material yang diriset?

Interpretasi :

- Deskripsikan dalam kalimat sederhana, material ini?

- Makna apa yang muncul dibenak pengguna ketika melihat material ini?

Afektif :

- Rasa emosi apa yang dirasakan pengguna ketika melihat material yang diriset? (terkejut, saying, benci, relax, dll)

Performative:

- Amati bagaimana pengguna berinteraksi dan bersikap dengan material yang diriset

Data - data FGD disarankan dirampung dalam bentuk mindmap, sehingga data - data yang relevan secara makna, emosi, sensorial, performa dapat langsung dihubungkan. Dari mindmap ini desainer dapat menarik kesimpulan mau menggunakan makna yang diidentifikasikan pengguna, memodifikasi makna yang sudah ada atau menkonstruksikan makna baru.

\section{B. Tahap 2. Membentuk Visi Pengalaman Material Kepada Pengguna}

Pada tahap ini, desainer memvisikan bagaimana peran material berkontribusi pada perfomansi sebuah produk dan menciptakan pengalaman sensorial yang unik ke pengguna; dan bagaimana material juga mempengaruhi hubungan antara produk yang satu dengan lain, orang lain dan dalam konteks penempatan yang berbeda. Selain data dari FGD, desainer juga diharuskan mencari studi - studi material yang diriset dan studi peran material bagi pengguna yang sudah ada sebelumnya. Bila material yang diriset benar - benar baru maka studi dapat dilakukan dengan membandingkan dengan material yang sejenis / mirip sehingga mendapatkan data yang dapat merefleksikan material tersebut.

\section{Tahap 3 Membentuk Pola Pengalaman Material}

Di tahap ini desainer membentuk pola pengalaman material dengan kreativitas dan imajinasinya sebagai desainer; bagaimana menghubungkan hasil riset teknis material, hasil FGD pengalaman 
pengguna pada material dan aplikasi produknya. Pada tahap ini desainer sudah harus membentuk satu kata kunci untuk konsep produknya yang merepresentasikan hubungan dimensi teknis, pengalaman dan produk aplikasi seperti feminine, high tech, dll.

\section{Tahap 4 Ideasi Konsep Produk}

Pada tahap ini, desainer merampungkan semua temuannya sebagai inspirasi dalam membentuk konsep desain. Dalam scenario material yang sudah ada dan belum umum konsep dapat dibentuk dari merubah kualitas sensorial material, misalnya tekstur, bentuk, dan teknologi produksi yang berbeda dari sebelumnya. Bila skenario material yang dalam tahap perkembangan, desainer dapat memainkan komposisi material penyusunnya, sehingga dapaat memberikan impresi pengalaman yang divisikan di tahap 3.

\subsection{Visual Analog Scale (VAS)}

Sebuah instrumen untuk mengukur intensitas perasaan seseorang akan sesuatu. VAS sering digunakan untuk mengukur rasa sakit seseorang di garis sepanjang $10-100 \mathrm{~cm}$, di ujung tidak ada sakit di ujung yang berlawanan rasa sakit yang tidak terbayangkan. VAS banyak digunakan dalam kuisoner yang berhubungan dengan kesehatan. Nilai intensitas perasaan seseorang didapatkan dari hasil ukur jarak. (National cancer insititute, 2018)

\section{METODE PENELITIANI}

\subsection{Eksperimen}

Teknik fusing adalah teknik memanaskan plastik untuk menggabungkan beberapa lembar plastik menjadi satu. Plastik yang dapat digunakan untuk teknik ini adalah plastik dengan jenis thermoplastic yaitu yang mudah meleleh karena panas. Proses fusing plastik sangat sederhana dan menggunakan peralatan yang mudah didapat. Melalui teknik fusing juga kita dapat memaksimalkan kekuatan plastik, sehingga dapat dipakai untuk jangka waktu yang lebih lama. Selain itu juga dapat memaksimalkan fungsi plastik, juga dapat berkreasi membuat produk yang baru.

\subsection{Pengukuran Pengalaman Material Plastic Fusing}

Penyebaran kuisoner yang disusun dengan pendekatan MDD dan pengukurannya dengan VAS.

\section{HASIL DAN ANALISA}

Hasil disusun berdasarkan tahapan dalam proses MDD:

\subsection{Tahap 1 Pemahaman properti material dan karakteristik pengalaman material}

Kantong plastik merupaka $n$ plastik thermoplastik jenis LDPE yang memiliki sifat - sifat sbb:

Tabel 1. Sifat Material LDPE (Strong, 2000)

\begin{tabular}{l|l} 
Sifat Material & \\
\hline Jenis Material & Polimer Sintetis \\
\hline Densitas & $0.910-0.925 \mathrm{~g} / \mathrm{cm} 3$ \\
\hline $\begin{array}{l}\text { Tg (Glass Transition } \\
\text { Temperature) }\end{array}$ & $-125 \mathrm{oC}(-193 \mathrm{~F})$ \\
\hline $\begin{array}{l}\text { Tm (Melting } \\
\text { Temperature) }\end{array}$ & $110 \mathrm{oC}(230 \mathrm{~F})$ \\
\hline Td (Decomposition & $335-450 \mathrm{oC}$
\end{tabular}




\begin{tabular}{l|l} 
Temperature) & \\
\hline Sifat Kimiawi & - Ductile4 tinggi \\
& - Tensile5 rendah \\
\hline Sifat Fisik / & - Semi-rigid \\
Karateristik & - Translucent \\
& - Fleksibel \\
& - Kuat \\
& - Tahan retak \\
& - Termoplastik \\
& - Tahan cuaca \\
& - Tahan zat kimia \\
& - Dapat didaur ulang
\end{tabular}

Setelah melakukan rangkaian eksperimen dengan proses seperti di gambar 1 :

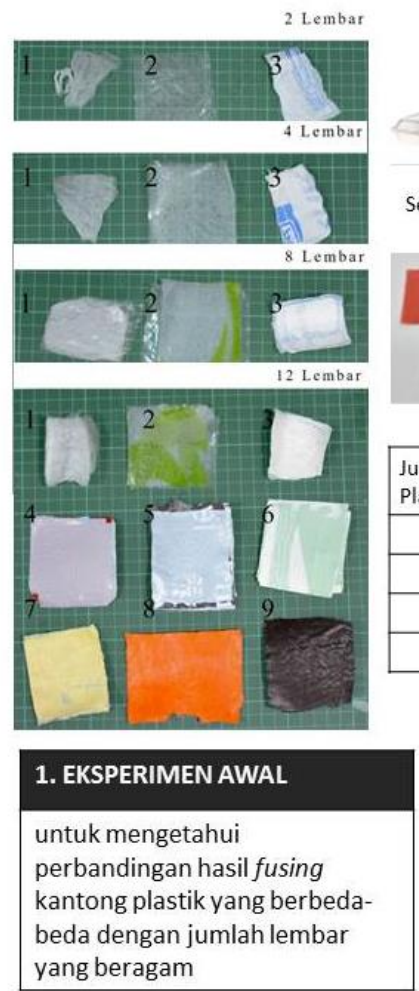

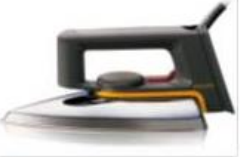

Setrika

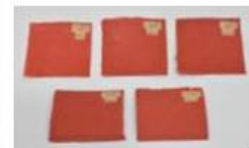

\begin{tabular}{|c|l|l|l|}
\hline \multirow{2}{*}{$\begin{array}{l}\text { Jumlah } \\
\text { Plastik (lbr) }\end{array}$} & \multirow{2}{*}{ Suhu $\left({ }^{\circ} \mathrm{C}\right)$} & \multicolumn{2}{|l|}{ Waktu (s) } \\
\cline { 3 - 4 } & & Sisi 1 & Sisi 2 \\
\hline 4 & 125 & 10 & 5 \\
\hline 8 & 150 & 5 & \\
\hline 10 & 150 & 5 & 5 \\
\hline 12 & 150 & 5 & 5 \\
\hline
\end{tabular}

2. EKSPERIMEN PERBANDINGAN ALAT

untuk mengetahui potensi alatalat yang memungkinkan untuk dipakai dalam fuse kantong plastik.

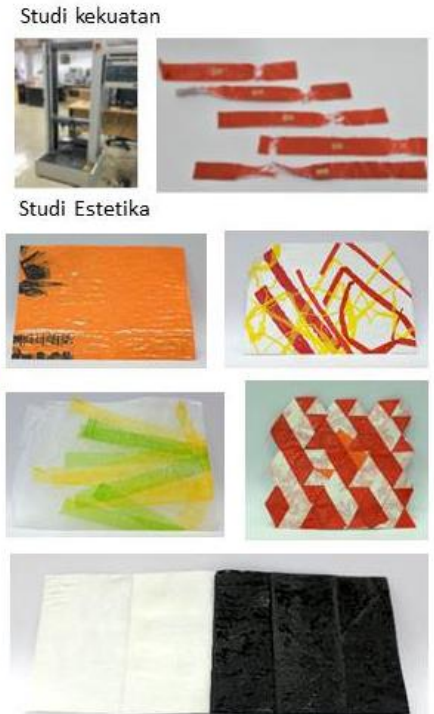

\section{STUDI-STUDI}

Untuk mengetahui potensi kantong plastikfusing dalam segi kekuatan dan estetika.

Gambar 1. Rangkaian Experimen

Setelah melakukan rangkaian eksperimen dirumuskan standard operating procedure yang aman dan terbaik untuk melakukan daur ulang kantong plastik.

1) Proses fusing menggunakan peralatan panas dilakukan pada ruangan dengan sirkulasi udara yang lancer. Lebih baik dilakukan di ruangan terbuka.

2) Pemakaian masker selama proses fusing.

3) Suhu maksimal untuk fusing sekitar $200^{\circ} \mathrm{C}$. Jangan sampai plastik terbakar, indikasinya adalah keluar gas dan plastik berubah warna.

4) Selalu gunakan pelapis seperti kalkir, seng maupun kain, agar peralatan panas tidak kontak langsung dengan plastik 


\subsection{Tahap 2 Pengukuran pengalaman material}

Kelima sample hasil eksperimen ditanyakan ke 50 responden via kuisoner. Responden diminta untuk memberi nilai dalam visual analog scale (VAS) range $1-10 \mathrm{~cm}$. Konten kuisoner disusun berdasarkan konsep material driven design (sensorial, interpretasi, afektif dan performative). Responden adalah mahasiswa desain komunikasi visual dengan rentan usia 20-21 tahun. Karakter plastic yang warna warni cocok untuk generasi millenials.

Tabel 2. Sample Material

\begin{tabular}{lcl}
\hline No. & Sampel Material & Foto \\
\hline 1. & Plastik bolong - bolong & \\
\hline 2. & Kombinasi warna kontras & \\
\hline 3. & Transparan & \\
\hline 4. & Anyaman & \\
\hline 5. & Lipat
\end{tabular}

Sample material favorit adalah sample no. 3 yang transparan dengan nilai 2.348 .76 (hasil penjumlahan semua nilai responden)

Hasil kuisioner diolah dengan software statistik Jamovi didapatkan hasil dari keempat aspek sensorial, interpretasi, afektif dan performative dianalisa mana yang saling mempengaruhi secara berurut:

1. Emotional dan performance, 0.496 (semakin tertarik semakin sering dipakai)

2. Opacity dan fleksibel, 0.453 (semakin transparan semakin flekslible)

3. Pola dan tekstur, 0.359 (semakin ada pola semakin perfect)

4. Tekstur dan emosional, 0.330 (semakin perfect maka semakin tertarik) 
dengan ukuran limbah kantong plastik. Keterbatasan ukuran tersebut dapat diakali dengan susunan modular, sehingga dapat menghasilkan lembaran plastik yang lebih besar dan beragam.

\subsection{Tahap 4 Ideasi Konsep Produk}

Berdasarkan hasil eksperimen, bahwa material kantong plastik fused ini tahan lama (durable) dan tahan air (waterproof). Oleh karena itu, produk yang dihasilkan nantinya dapat diletakkan indoor maupun outdoor. Material hasil daur ulang kantong plastik hasil fusing ini berpotensi untuk dijadikan produk dari berbagai kategori seperti home décor, tas, dompet, maupun produk lighting. Dengan berbagai macam warna, motif dan desain yang dapat ditemukan dari limbah kantong plastik, produk akan memiliki keunikan yang berbeda satu sama lain. Hasil pengujian kekuatan kantong plastik fused juga menyimpulkan bahwa semakin tebal, plastik semakin kuat.

Produk Dompet Kartu dibuat dengan teknik lipat, karena dengan satu material ini bisa kuat tanpa perlu material pendukung yang banyak, sehingga lebih ramah lingkungan, dan tidak membutuhkan energi tambahan untuk memproduksinya.

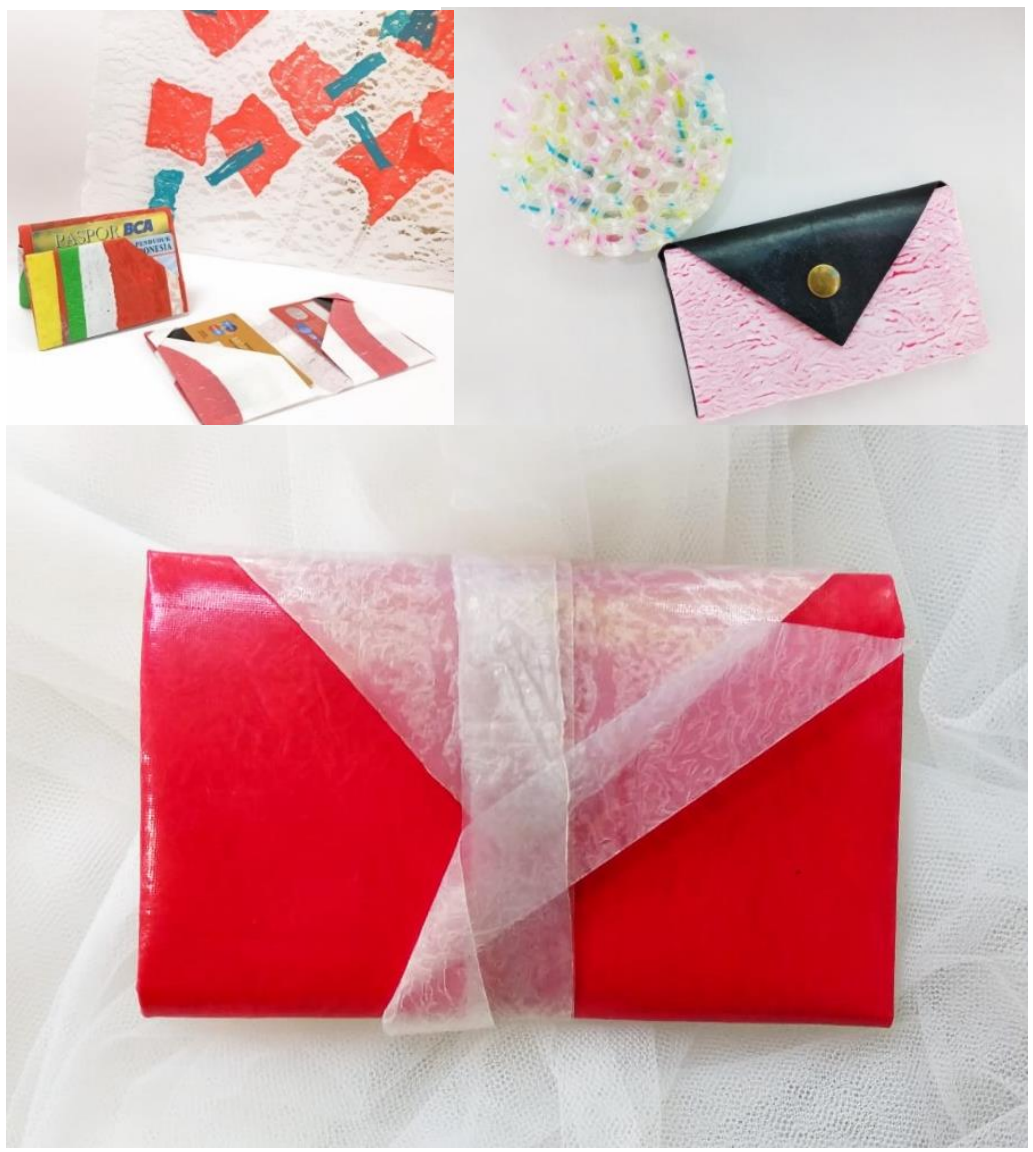

Gambar 2. Dompet Kartu Origami 


\section{KESIMPULAN, SARAN, DAN RENCANA KEBERLANJUTAN PENELITIAN}

Dari penelitian ini dapat disimpulkan bahwa konsep material driven design (MDD) cukup berhasil membawa material kantong plastic keluar dari persepsinya sebagai limbah menjadi material baru, karena ketika penyebaran kuisoner banyak orang tidak tahu bahwa ini adalah kantong plastic. Proses MDD membantu peneliti menjadi lebih terstruktur dalam proses meneliti tidak hanya melihat material dari segi teknis tapi juga melihat dari semua aspek yaitu sensorial, interpretasi, afektif dan perfomatif. Kebaruan penelitian ini dari penelitian bertopik MDD sebelumnya adalah penggunaan visual analog scale dalam mengukur intensitas perasaan responden ketika melihat dan berinteraksi dengan material ini. Dengan analisa statistic sederhana melalui software Jamovi dapat dianalisa bahwa keempat factor yaitu sensorial, interpretasi, afektif dan perfomatif saling mempengaruhi dalam pembentukan persepsi material pada responden. Dari 50 responden dapat diamati bahwa yang paling mempengaruhi adalah faktor emosi dan performatif. Persepsi material plastic fusing yang paling disukai responden adalah pola, warna kontras dan transparan. Ketiga persepsi ini yang dikembangkan dalam produk hasil penelitian dompet.

Rekomendasi desain bila mendesain produk dengan material ini adalah, membuat pola abstrak dari kantong plastik, kombinasi warna kontras dan transparan, karena ketiga hal ini yang disukai pengguna akan material ini.

Untuk produk tingkat kerapihan pembuatan produk perlu ditingkatkan, karena bila tidak rapih dan presisi kesan kreseknya akan kembali muncul dan orang akan mempersepsikan produk ini sebagai produk murahan, terutama untuk produk origami, karena terkadang pattern dari material plastic fusing yang menolak arah lipatan, sehingga lipatan tidak presisi. Maka saat melipat perlu dibantu setrika untuk menekan agar lipatan rapih.

Kendala yang dialami selama penelitian adalah sumber limbah kantong plastic yang masih minim, karena masih banyak orang yang ingin menggunakan kantong plastik untuk kantong sampah. Jadi enggan untuk memberikan sampahnya. Padahal menggunakan kantong plastic supermarket untuk tempat sampah adalah tidak benar, karena plastic ini akan hancur menjadi micro plastic yang tidak akan terurai. Lebih baik plastik ini dipanaskan dengan teknik fusing sehingga memperpanjang kegunaannya. Oleh karena itu, akan sangat menarik bila penelitian ini dilanjutkan dengan pendekatan service design untuk mengumpulkan sampah kantong plastic, agar hasil penelitian dapat diperbesar skalanya. Jadi orang memberikan limbahnya sebagai imbalannya akan mendapat produk pakai.

\section{UCAPAN TERIMA KASIH}

Penulis ingin mengucapkan terima kasih atas bantuan, bimbingan serta kerjasama dari berbagai pihak yang telah membantu dalam penyusunan karya ilmiah ini. Penulis menyampaikan terima kasih kepada:

- Dr. Martin L. Katoppo S.T, M.T.selaku Dekan Fakultas Desain Universitas Pelita Harapan

- Dr.-Ing. Ihan Martoyo, S.T., M.Sc selaku Ketua LPPM Universitas Pelita Harapan

- Artikel ini merupakan publikasi penelitian internal UPH dengan no. No. 187/LPPM$\mathrm{UPH} / \mathrm{VI} / 2018$ 


\section{REFERENSI}

AdhesiveandGlue. Thermoset - Definition and Examples of Thermosets. April 22, 2018. http://www.adhesiveandglue.com/thermoset.html.

Ashby, M., \& Cebon, D. (2007). Teaching engineering materials: The CES EduPack. Retrieved June 1, 2015, from http://web.mit.edu/course/3/3.225/refs/Teaching_Engineering_Materials.pdf

Ashby, M., \& Johnson, K. (2009). Materials and design. The art and science of material selection in product design ( $2^{\text {nd }}$ ed.). Oxford, UK: Butterworth-Heinemann Elsevier.

Karana, E., (2009). Meanings of materials (Doctoral dissertation). Delft University of Technology, Delft, the Netherlands.

Strong, A. Brent. (2000) "Definitions of Plastics and Polymers." In Plastics: Materials and Processing, by A. Brent Strong, 1. New Jersey: Prentice-Hall, Inc.

Council, American Chemistry. How Plastics Are Made, Inc. 20117. https://plastics.americanchemistry.com/How-Plastics-Are-Made/. Dadachanji, Dinshaw. Uses of Thermoplastics. April 22, 2018.

Karana, E., Barati, B., Rognoli, V., \& Zeeuw van der Laan, A. (2015). Material driven design (MDD): A method to design for material experiences. International Journal of Design, 9(2), 35-54.

Plastics, Modor. Thermoset and Thermoplastic. (2018) http://www.modorplastics.com/thermoset-vsthermoplastics.

Utomo, Yunanto Wiji. Indonesia Penghasil Sampah Plastik Kedua Terbesar di Dunia. Agustus 7, 2016. http://nationalgeographic.co.id/berita/2016/08/indonesia-penghasil-sampah-plastik-kedua-terbesardi-dunia. 